\title{
O Itamaraty nos anos de chumbo - O Centro de Informações do Exterior (CIEX) e a rep ressão no Cone Sul (1966-1979)
}

\author{
Itamaraty at the years of lead - The Center \\ of Foreign Information (CIEX) and repression \\ in the Southern Cone (1966-1979)
}

PIO PENNA FILHO*

Rev. Bras. Polit. Int. 52 (2): 43-62 [2009]

\section{Introdução}

As ditaduras militares que marcaram a história recente dos países do Cone Sul deixaram raízes que por muito tempo e ainda permanecerão vivas na memória de várias gerações. Embora os acontecimentos políticos e sociais vivenciados no Cone Sul durante as décadas de 1960 e 1970 do século XX sejam eventos ainda recentes em termos históricos, já é possível começar a compreender melhor esse importante período da nossa história com certo grau de isenção e de objetividade. Pode-se dizer que estamos começando a sair do campo da memória para entrar no campo da história propriamente dita, sobretudo com a gradativa liberação de fontes primárias até então guardadas a sete chaves.

Este trabalho é baseado principalmente na análise do funcionamento do Centro de Informações do Exterior (CIEX), órgão do Itamaraty e vinculado ao Serviço Nacional de Informações (SNI) que foi encarregado de espionar políticos e militantes contrários ao regime militar brasileiro que se exilaram nos países vizinhos. Trata-se, portanto, de um estudo que visa a desvendar como agia um dos elos do sistema repressivo montado pela ditadura brasileira que tinha relativo grau de interação com as outras ditaduras militares da região.

O objetivo desse artigo é apresentar as atividades do CIEX somente na região do Cone Sul, entre os anos de 1966, data da sua criação, e 1979, com a anistia e o retorno de parte dos exilados. Com efeito, o Centro desempenhou atividades também na Europa, sobretudo em Portugal, para onde muitos exilados brasileiros se dirigiram após a onda de ditaduras que varreu a democracia do Cone Sul. Todavia,

\footnotetext{
* Professor do Instituto de Relações Internacionais da Universidade de São Paulo - IRI-USP e Pesquisador do Conselho Nacional de Desenvolvimento Científico e Tecnológico - CNPq (piopenna@gmail.com).
} 
por uma questão de espaço e de pesquisas ainda em andamento, as atividades relacionadas a segunda fase de atuação do Centro ficarão para outro momento.

Um dos primeiros aspectos a ressaltar é que a pesquisa derruba o mito de que o Itamaraty não colaborou ou colaborou pouco com o lado mais sombrio da ditadura militar brasileira. Por muitos anos, gerações de diplomatas afirmaram que a tradição e a autonomia desfrutada pelo Ministério das Relações Exteriores no âmbito do serviço público teria lhes permitido evitar uma associação com a repressão generalizada que se instalou no país após o Golpe de Estado de 1964. Tal, de fato, não ocorreu. Houve a colaboração em diversos níveis, seja participando ativamente do processo de "depuração" interna promovida pelos inquéritos ideológicos no período inicial da ditadura, seja montando um aparato de espionagem que atuava preferencialmente nos países onde havia maior número de exilados brasileiros. Sua colaboração foi estreita com as principais agências responsáveis pela repressão no Brasil, como o temido SNI, com o Exército, com a Marinha e com a Aeronáutica, por meio de suas respectivas agências especializadas, a saber: o CIE, o Cenimar e o CISA.

\section{As ditaduras no cone sul e a repressão além-fronteiras}

Durante o período das ditaduras latino-americanas nas décadas de 1960 e 1970, houve uma intensa cooperação entre os serviços de segurança nacionais, seja por meio de ações de inteligência na troca de informações, seja pela cooperação perversa dos sistemas de repressão efetivos, os quais iam muito além do plano da inteligência para medidas concretas de eliminação dos oponentes/resistentes às diversas ditaduras militares instaladas nos países sul-americanos, especialmente no âmbito do Cone Sul ${ }^{1}$. Embora já houvesse essa percepção por parte dos exilados, ou seja, de que eram monitorados por agentes policiais ou agentes ligados à repressão nos países onde estavam, a comprovação documental definitiva, assim como a extensão das operações da repressão, só vieram à tona com a descoberta dos chamados "Arquivos do Terror", no Paraguai (GUENA, 1996).

A região do Cone Sul passou por momentos conturbados durante as décadas de 1960 e 1970, período em que todos os países da região ficaram submetidos por ditaduras militares. Assim, sem exceção, todos passaram por um ou mais de um golpe militar, geralmente reformulando as relações internas de poder e a forma do exercício da política no interior dos Estados nacionais. Apesar de terem se constituído, na região, regimes distintos, todos tinham em comum um profundo discurso anticomunista e buscaram respaldar sua legitimidade na ideologia da segurança nacional ${ }^{2}$.

1 O Cone Sul da América do Sul é formado por Brasil, Argentina, Paraguai, Uruguai, Bolívia e Chile.

2 Um caso atípico mas que logo se adequou ao contexto histórico foi o do Paraguai. Nesse país o golpe de Estado veio antes, em 1954, e respondeu nem tanto a uma polarização ideológica interna, mas antes ao quadro de instabilidade política e de divergências entre oligarquias rivais. De toda forma, foi uma questão de tempo para que a ditadura de Stroessner logo se adequasse aos pressupostos da ideologia de segurança nacional. 
Outro aspecto em comum é que todos os regimes basearam-se em intensa repressão para a imposição de sua vontade política, colocando definitivamente a democracia para escanteio. É importante ainda destacar que, para a maioria dos países, foram regimes que se estabeleceram para ficar um longo período no controle do aparato do Estado, criando uma dinâmica própria que trabalhava para a manutenção, a todo custo, da nova ordem amparada na chamada Doutrina de Segurança Nacional (DSN).

Havia muitos interesses em jogo e a explicação da tomada de poder por meio de jargões batidos como "ofensiva imperialista norte-americana" não servem para explicar a tomada do poder pelos militares e mesmo a manutenção daqueles regimes. Vários segmentos das elites nacionais em todos os países do Cone Sul esforçaram-se para minar políticas de cunho social que vinham sendo ensaiadas por governos ditos populares. Foi assim no Chile e, em parte, no Brasil, por exemplo. Mas em todos se verificou logo um entrosamento entre setores militares e civis da sociedade.

Uma questão que gradativamente está sendo revelada com a liberação de documentos classificados diz respeito aos aspectos regionais relacionados às ditaduras no Cone Sul. Hoje sabemos, por meio de documentos, que os militares brasileiros ajudaram a desestabilizar regimes de outros países, como foi o caso do Uruguai e, mais recentemente, com a revelação de que o Brasil, durante o governo do presidente Médici, trabalhava para derrubar Salvador Allende. Pelo menos é a informação que consta no relato da conversa entre Médici e Nixon ocorrida em 9 de dezembro de 1971, no Salão Oval da Casa Branca³.

Além disso, o que boa parte dos analistas sobre aquele período não discutem é o papel das próprias esquerdas no acirramento do confronto ideológico de então. Tendo como pano de fundo o cenário da Guerra Fria e a existência concreta de uma alternativa ao mundo capitalista, vários partidos ou movimentos de esquerda, como o MIR chileno, os Tupamaros uruguaios e os Montoneros na Argentina, lutavam em nome de revoluçôes de cunho socialista, muitos deles inspirados no modelo cubano ou chinês, haja vista que naquele momento a linha soviética se apresentava por demais moderada e conservadora. Verificou-se, portanto e efetivamente, uma polarização entre esquerda e direita que não era somente imaginária, mas real. Nesse sentido, o que a direita dos países em questão fez foi potencializar a ameaça de mudança proposta pela esquerda, uma vez que não podemos nos esquecer que muito pouco havia de democrático nas propostas desses diversos partidos e movimentos de esquerda. Aliás, a sua inspiração provinha dos modelos mais autoritários possíveis, como o chinês, o cubano e o albanês. E não só o Estado e grupos políticos de direita foram responsáveis pela criação ou ampliação da ameaça "vermelha".

Outro ponto importante que devemos pensar quando analisamos o que ocorreu no plano regional durante os anos 1960 e 1970 diz respeito à cooperação

3 Ver: "Meeting with President Emílio Garrastazu Médici of Brazil on Thursday, December 9, 1971, at 10:00 a.m., in the President's Office, the White House”. Disponível em http://www.gwu.edu/\%7Ensarchiv/ NSAEBB/NSAEBB282/index.htm disponibilidade: 16/08/2009. 
e à interação entre os aparelhos repressivos criados pelas ditaduras. Todas elas, com efeito, criaram ou modificaram agências de informaçóes ou adequaram suas instituições voltadas tradicionalmente para a defesa do Estado. Sua nova função deveria ser o combate ao inimigo interno, estivesse ele onde estivesse, ou seja, dentro das fronteiras do Estado ou fora dela. E o inimigo interno era justamente aquele previamente identificado como comunista, embora o significado dessa palavra estivesse muito mais vinculado ao fato de se opor ao regime, do que efetivamente a uma filiação ideológica.

No plano das informações e especialmente analisando o caso do Brasil, o objetivo da ditadura era estar sempre um passo à frente daqueles que contestavam o regime, seja no país ou fora dele. A função maior do CIEX era justamente essa: monitorar, vigiar e seguir os passos dos exilados brasileiros que ainda estavam na atividade política e não aceitavam a nova ordem, abastecendo a dita comunidade nacional de informações a par do que acontecia no exterior ${ }^{4}$. Mas mesmo antes da criação do CIEX, que só ocorreu em 1966, algumas embaixadas brasileiras já faziam o serviço de monitoramento dos exilados brasileiros.

A coleta de informaçōes estratégicas para o Estado também constava de suas funções, assim como análises de conjuntura política, econômica e militar sobre os países vizinhos ou aqueles que de alguma forma pudessem interessar ao Brasil, como os Estados socialistas, por exemplo, para os quais havia uma atenção especial, sobretudo quando eram identificadas conexões com movimentos de esquerda ou pessoas no Brasil. Um exemplo claro nesse sentido eram as atividades desenvolvidas pela embaixada brasileira em Praga, que entre o final da década de 1960 e início da seguinte mantinha sistematicamente o Itamaraty informado sobre a movimentação de brasileiros na antiga Tchecoslováquia ou que estivessem apenas em trânsito para a ex-União Soviética. Em 1968, por exemplo, o CIEX produziu o informe 603 que foi difundido para o SNI, para o CIE e para a 2a Seção do Estado Maior do Exército prestando a informação de que o asilado brasileiro Benedito Cerqueira havia solicitado à Embaixada brasileira em Praga a concessão de passaporte e que expressava o seu interessava em retornar ao Brasil, não o tendo feito até aquele momento por medo de ser preso ao desembarcar 5 .

\footnotetext{
4 Sobre a atuação do CIEX ver: PENNA FILHO, Pio. O Itamaraty e a Repressão Além-Fronteiras: o Centro de Informações do Exterior - CIEX (1966-1986). In: Carlos Fico; Maria Paula Araújo; Celso Castro; Ismênia de Lima Martins; Jessie Jane Vieira de Sousa; Samantha Viz Quadrat. (Org.). 1964-2004-40 Anos do Golpe - Ditadura Militar e Resistência no Brasil. Rio de Janeiro: Viveiros de Castro Editora Ltda -7 Letras, 2004, v. , p. 163-169.

5 Cf. CIEX, Informe n. 603, "Asilado brasileiro na Tchecoslováquia. Benedito Cerqueira". 10 de outubro de 1968. Secreto. CIEX, vol. 7, 1968. As informaçōes provenientes da ex-Tchecoslováquia geraram pelo menos um ofício do Ministro das Relações Exteriores para o Ministro do Exército, informando-o sobre a "utilização de Praga como etapa no encaminhamento para o Brasil de elementos treinados em Cuba para atividades guerrilheiras". Ver: "Atividades subversivas no Brasil, utilizando da Tcheco-Eslováquia por elementos treinados em Cuba". Ofício n. 42, de José de Magalhães Pinto, Ministro das Relaçōes Exteriores, para o general de Exército Aurélio de Lyra Tavares, Ministro do Exército. 29 de agosto de 1969. Arquivo do Ministério das Relações Exteriores, caixa SL LXVIII, 601.3 (00) - Revoluções, Rebeliōes, Revoltas e etc. Secreto. Ver, por
} 
Todavia, o volume de informes dedicados à pura espionagem política contra cidadãos brasileiros vivendo no exterior superava, e em muito, as análises estratégicas e de conjuntura política e econômica de outros Estados. Esse foi o padrão na atuação do CIEX entre 1966, ano de criação do Centro, e 1979, quando da decretação da Anistia e do retorno ao país da maior parte dos exilados brasileiros. Nesse sentido, o CIEX teve de se adaptar aos novos tempos que se prenunciavam com a lenta e gradual abertura do regime, muito embora não tenha perdido seus vícios de origem, como não poderia deixar de ser.

Apesar, por exemplo, de todo o contexto de abertura gradual deslanchado pelo governo Geisel, com o enquadramento da linha dura que não admitia a transferência de poder para os civis, isso não afetou as atividades do CIEX. Os diplomatas brasileiros encarregados de acompanhar as atividades dos exilados continuaram o seu trabalho normalmente, mesmo porque reportavam-se diretamente aos outros órgãos que compunham a comunidade de informaçôes. O Centro era, na verdade, uma agência que funcionava com grande autonomia na estrutura administrativa do Itamaraty. Embora tenha sido estruturado com quadros do Ministério, tendo à frente sempre um diplomata de nível intermediário (como Ministro ou Conselheiro), hierarquicamente subordinava-se, na prática, ao SNI.

Voltando ao contexto regional e retomando a discussão sobre a cooperação e interação entre os aparelhos repressivos, este foi um aspecto imprescindível para o sucesso das operações da repressão nos países do Cone Sul. Sem que houvesse cooperação entre as forças policiais e militares envolvidas no combate aos grupos que se organizavam em diversos países com conexões bem estabelecidas, muito dificilmente esses grupos de atuação transnacional teriam sido desmantelados com a rapidez com que o foram.

A rigor, não se pode dizer que tenha existido uma integração dos sistemas de repressão no Cone Sul. Houve de fato a tentativa de criação de um sistema integrado, mas de maneira parcial e só bem depois do Golpe de Estado no Brasil. A mais conhecida de todas foi uma iniciativa chilena, denominada Operação Condor.

A idéia da Operação Condor era criar de fato uma agência internacional que coordenasse atividades contra os grupos que contestavam as ditaduras militares do Cone Sul. A primeira reunião internacional para sua criação ocorreu no Chile, em 1976, e dela participaram representantes do Chile, Brasil, Argentina, Uruguai e Paraguai. Embora os norte-americanos não tenham participado, acompanharam de perto as decisões tomadas na reunião. Essa era uma prática relativamente comum, ou seja, como potência hegemônica do Ocidente, os países

exemplo: "Atividades Políticas. Daniel Lins". Ofício n. 163, da Embaixada do Brasil em Praga, para a Secretaria de Estado. Praga, 9 de abril de 1973. Confidencial. "Luiz Tenório Lima. Viagem para o Brasil". Ofício n. 207, da Embaixada do Brasil em Praga para a Secretaria de Estado. Praga, 4 de maio de 1973. Confidencial. "Paulo do Amparo. Regresso ao Brasil". Ofício n. 221, da Embaixada do Brasil em Praga, para a Secretaria de Estado. Praga, 15 de maio de 1973. Confidencial. "Atividades dos comunistas brasileiros no movimento sindical". Ofício n. 356, da Embaixada do Brasil em Praga, para a Secretaria de Estado. Praga, 21 de agosto de 1973. Confidencial. 
latino-americanos geralmente mantinham os Estados Unidos informados sobre suas atividades de repressão internacional e, eventualmente, recorriam ao auxílio norte-americano. Houve, nesse sentido, uma intensa troca de informaçóes entre os serviços secretos dos países do Cone Sul e as agências de segurança do Estados Unidos da América. ${ }^{6}$

Muito tem sido dito no Brasil sobre a Operação Condor. A imprensa brasileira chegou a publicar várias matérias sobre o assunto. Contudo, aqui defende-se a tese de que essa Operação não interessava efetivamente ao governo brasileiro, à época dirigido por Ernesto Geisel. O Brasil preferiu não se envolver tão diretamente e não se comprometer tanto com o esquema vislumbrado pelos chilenos e acompanhados com certo entusiasmo pela Argentina e pelo Paraguai. E por quê a ditadura brasileira não se interessou tanto pela Condor?

Ora, em 1976, ano de criação do Operativo Condor, os focos de resistência à ditadura no Brasil já haviam sido virtualmente eliminados pelo regime, restando muito pouca capacidade para a atuação dos grupos de esquerda remanescentes no País. Já no contexto regional, o fim das democracias no Uruguai, no Chile e, finalmente, na Argentina, fechou o cerco ao amplo movimento de exilados entre as fronteiras desses Estados. A essa altura, os brasileiros que haviam originalmente buscado refúgio na região do Cone Sul se viram impedidos de continuar nessa área, sobretudo pela ferocidade dos regimes chileno e argentino, que foram implacáveis com qualquer tipo de pensamento de esquerda. Era necessário e urgente buscar refúgio em outras partes, seja na Europa, América do Norte ou África, muito longe, portanto, das fronteiras nacionais.

O estudo da documentação do CIEX demonstra claramente essa mudança de eixo, ou seja, multiplicaram-se os informes provenientes da Europa, principalmente de Portugal, para onde migrou grande parte dos exilados brasileiros que se encontravam na América do Sul7. Também dos Estados Unidos e da África começaram, eventualmente, a chegar informes sobre a presença de brasileiros naquelas regiōes. No caso da África, a opção era pelas ex-colônias portuguesas, especialmente Moçambique e Angola, que tentava uma experiência "socialista".

6 No arquivo do Itamaraty em Brasília existem várias pastas, por exemplo, contendo exclusivamente documentos trocados entre o Brasil e agências norte-americanas sobre atividades políticas designadas genericamente de "comunistas" na América Latina. Ressalte-se que esses documentos não estão organizados (pelo menos não estavam) e nem disponíveis para consulta. Embora ainda não seja possível comprovar por meio de documentos, é razoável supor que houve algum tipo de troca de informações entre o SNI e agências como a CIA. Prova dessa difusão para o exterior de material coletado por meio de agências como o CIEX (e também as dos então ministérios militares) pode ser observada em alguns documentos, como a citação que se segue: "Nota do CIEX: - O presente informe não deverá ser transmitido a qualquer serviço estrangeiro". Índice: Raul Bidegain Greissing. Atividades. MRE/Centro de Informaçōes do Exterior - n. 353/73, 10 de julho de 1973. Informe, avaliação C-3. Difundido para: SNI/AC, CIE, $2^{\mathrm{a}}$ Sec/EME, $2^{\mathrm{a}}$ Sec/EMAER, Cenimar, $2^{\mathrm{a}}$ Sec/EMA, DSI/MRE, CISA, CI/DPF. CIEX, Vol. 19, 1973. Secreto.

7 Ver, especialmente, os volumes de número 22 a 26 (1974-1978) do CIEX. Acervo do autor. Infelizmente esses documentos ainda não estão totalmente disponíveis para pesquisa, mas no momento encontram-se no Arquivo Nacional em Brasília, onde estão sendo classificados e preparados para disponibilização ao público de acordo com a legislação nacional vigente que é, infelizmente, uma das mais restritivas e atrasadas do mundo. 
Nesse continente ainda se deve citar a presença de brasileiros na Argélia, país escolhido por seu regime de esquerda e promotor dos princípios da descolonização e do socialismo. A preferência, porém, recaía sobre Portugal. Muito além do idioma, a Revolução dos Cravos, ocorrida em 1974, e a conseqüente redemocratização do país abria muitas possibilidades para os exilados brasileiros.

Se no Brasil praticamente não havia mais guerrilha em atividade, tal não se dava na Argentina. Lá, os militantes ligados ao Exército Revolucionário do Povo (ERP) e os mais extremistas militantes vinculados aos Montoneros ainda tentavam promover a revolução socialista e estavam em franca campanha contra a ditadura militar, apesar da luta desigual e da repressão implacável. Registre-se também o trânsito frequente de militantes contrários à ditadura de Stroessner no norte da Argentina, em cidades próximas às zonas de fronteira como Posadas.

A Operação Condor não se destinava apenas a combater guerrilheiros ou movimentos de esquerda atuando transnacionalmente. Lideranças políticas tradicionais, geralmente comprometidas com a democracia e que pudessem de alguma maneira prejudicar ou embaraçar os regimes militares também se constituíram em alvo. O exemplo mais ousado do emprego das garras do Condor foi o assassinato, em plena capital norte-americana, do ex-Chanceler chileno Orlando Letelier, que contou inclusive com a anuência ou, no mínimo, a omissão do governo dos Estados Unidos, que acompanhava, por meio da CIA, as atividades do Operativo Condor e nada fez para impedir o atentado ${ }^{8}$. O assassinato de Letelier mostrou, além da ousadia e autoconfiança dos militares-terroristas vinculados ao Operativo, sua capacidade operacional, haja vista que foi um ato espetacular, quase cinematográfico. Uma bomba foi colocada sob o automóvel particular de Letelier explodindo de maneira letal enquanto o mesmo se deslocava por Washington.

A atitude dos Estados Unidos perante o assassinato de Letelier coloca-nos uma questão importante, que está relacionada à participação dos norte-americanos com o terrorismo de Estado existente no Cone Sul. Sem dúvida alguma, um grande facilitador para a cooperação entre os militares do Cone Sul e, no geral, da América Latina, foram os Estados Unidos da América e sua política de combate ao comunismo no plano continental. Os freqüentes cursos de especialização e treinamento que os oficiais militares latino-americanos recebiam em academias militares norte-americanas, especialmente na famosa Escola das Américas principalmente a partir da segunda metade da década de 1960, quando houve um recrudescimento do embate ideológico na América Latina, criaram um clima propício para uma maior aproximação entre as forças armadas ali treinadas, que incluíam oficiais de praticamente todos os países do continente. Nesses cursos, como destaca Esteban Cuya, investigador do Centro de Direitos Humanos de Nuremberg, forjavam-se laços de amizade e confiança que mais tarde seriam de grande valia

8 Cf. DINGES, John. Operación Condor - una década de terrorismo internacional en el Cono Sur. Santiago: Crônica Atual, 2004, p.222. 
para o bom entendimento e viabilidade operacional entre os oficiais envolvidos no combate à "subversão". ${ }^{9}$ No caso brasileiro, como afirmou o general Octávio Costa em depoimento a Maria Celina D’Araujo e Gláucio Ary Dillon Soares, antes que o SNI criasse sua própria doutrina, oficiais brasileiros estudaram em escolas de informações dos Estados Unidos (D'ARAUJO; SOARES; CASTRO, 1994).

A Escola das Américas foi criada no Panamá em 1946, pelo governo dos Estados Unidos. Seu objetivo oficial era o de promover a estabilidade política na região, mas o curioso é que sobre ela pesam sérias acusaçōes de violação dos direitos humanos e de ter se tornado a maior base de desestabilização política da América Latina, uma vez que sua doutrina de combate ao inimigo interno no contexto da Guerra Fria favoreceu enormemente o estabelecimento de regimes de exceção, geralmente ditaduras militares. As acusações vão além e há evidências de que ao longo do tempo os militares latino-americanos foram treinados em técnicas de tortura e guerra psicológica, voltadas de forma direta contra os seus próprios cidadãos. Isso ficou claro com a divulgação de manuais de treinamento editados em espanhol e que eram empregados pela Escola. Neles se ensinavam técnicas de interrogação, tortura, execução, chantagem e captura dos parentes das pessoas que estavam sendo interrogadas. Em 1984 a Escola, que também foi apelidada de "Escola de Golpes", foi transferida para Fort Benning, no Estado norte-americano da Geórgia, onde continua suas atividades de treinamento de militares latino-americanos.

No caso da ditadura brasileira, muitos foram os militares enviados para cursos de treinamento patrocinados pela Escola. De acordo com uma pesquisa realizada pelo Grupo Tortura Nunca Mais/RJ, entre 1954 e 1995, entre os vários brasileiros que tiveram treinamento na Escola estavam pelo menos dois instrutores e dezenove alunos que estiveram diretamente envolvidos com a tortura política e com o aparato da repressão no Brasil pós-Golpe. A maior parte dos citados pelo Grupo Tortura Nunca Mais era de oficiais e sargentos das Forças Armadas, mas também havia entre eles um oficial da Polícia Militar do Paraná e outro da Polícia Militar de Pernambuco. Esses militares acabaram atuando diretamente na repressão, principalmente no Centro de Informações do Exército (CIE), no Centro de Informaçōes e Segurança da Aeronáutica (CISA), no Centro de Informaçōes da Marinha (Cenimar) e nos Destacamentos de Operações de Informações - Centro de Operações de Defesa Interna (Doi-Codi). Alguns ganharam destaque ao longo de sua carreira, como o oficial da Aeronáutica João Paulo Moreira Burnier - envolvido no caso Parasar (1968) - e o do Exército, Helio Lima Ibiapina, que chegou a presidir o Clube Militar no Rio de Janeiro. ${ }^{10}$

9 Ver: "La Operación Condor: El Terrorismo de Estado de Alcance Transnacional". Disponível em: www. derechos.org/koaga/vii/2/cuya disponibilidade: 16/08/2009.

10 “Análise de Instrutores e Alunos Brasileiros da 'School of Americas'. Disponível em: www.dhnet.org.br/ denuncias/tortura/escola/analise/html disponibilidade: 16/08/2009. 


\section{O exílio e a vigilância}

O exílio não significou o fim da política para os banidos ou para aqueles que saíram antes de caírem prisioneiros. Tão logo os ativistas e militantes se estabeleciam num novo país, começava um processo de reagrupamento que geralmente seguia as lideranças de origem. Ou seja, a tendência natural era a formação de grupos que já possuíam alguma identidade ideológica ou que orbitavam em torno de uma liderança específica, com capacidade de dar algum tipo de suporte e auxílio para os difíceis tempos que viriam. Mas havia exceções, isto é, novas composições políticas eram feitas de acordo com a nova realidade. A princípio a condição de exilado e a vulnerabilidade dessa condição facilitava ou impunha arranjos e alianças em torno de lideranças já estabelecidas nos países de exílio. Citemos um exemplo: o caso do Uruguai, primeiro país a receber número significativo de brasileiros no exterior.

No Uruguai, em torno de Leonel Brizola e João Goulart foram formados praticamente dois núcleos bem estabelecidos de exilados que se reuniram não só por afinidade ideológica, mas também porque ambos haviam criado esquemas para recepcionar e viabilizar a vida dos exilados que chegavam àquele país ${ }^{11}$. Tanto Brizola quanto Goulart, em parte por serem gaúchos e por isso mesmo já terem algum tipo de relação com os uruguaios, podiam amenizar as dificuldades inerentes à vida num novo país.

Além disso, o processo de regularização oficial de um exilado costumava ser demorado e foi muito comum que para muitos brasileiros que tiveram que sair do país apressadamente aquela estava sendo a primeira experiência no exterior. Assim, é possível imaginar como as dificuldades do estabelecimento num outro país era custosa para homens e mulheres que geralmente sequer falavam outra língua além do português e que repentinamente não podiam mais viver em seu próprio país. Isso sem contar com as dificuldades de natureza financeira, que certamente complicavam a vida daqueles que eram obrigados a se exilar. A solução dessa questão valia, naturalmente, para reforçar os esquemas de vinculação política com as lideranças já estabelecidas.

No caso especifico do Uruguai, que foi o primeiro país a receber um fluxo considerável de exilados brasileiros, a embaixada em Montevidéu logo se adaptou aos novos tempos e às novas funçôes. No segundo semestre de 1964 já transitava pela embaixada um informante credenciado pela Divisão de Ordem Política e Social do Departamento de Polícia Civil do Estado do Rio Grande do Sul ${ }^{12}$. Sua função era coletar informações sobre as atividades dos brasileiros na capital uruguaia que

11 Ver: "Estudo sobre as atividades dos exilados brasileiros no Uruguai". CIEX Volume 2, doc. n. 687, Secreto, 29/12/1966. Acervo do autor.

12 "Asilados brasileiros no Uruguai. Atividades da DOPS do Rio Grande do Sul". Ofício n. 652, expedido pela Embaixada do Brasil em Montevidéu para a Secretaria de Estado. 11 de dezembro de 1964. Arquivo do Ministério das Relações Exteriores, Ofícios Recebidos - 1964 - A/O, caixa 07 - Secreto. 
seriam remetidas para o Brasil. Além das atividades de espionagem, a Embaixada tentou fazer com que Brasília tomasse uma atitude mais consistente com relação ao "problema" dos exilados brasileiros no Uruguai, tratando o assunto no nível político bilateral. Em longo ofício à Secretaria de Estado, o embaixador brasileiro solicitava que o Itamaraty avaliasse a possibilidade de provocar uma definição do governo uruguaio quanto a presença e atividades dos exilados brasileiros. Dentre as medidas sugeridas constavam a "apreensão de aeronaves em poder dos asilados ou a seu serviço", a "vigilância estrita dos movimentos dos asilados e refugiados", a "verificação constante do paradeiro dos asilados e refugiados, com obrigação de apresentarem-se frequentemente a autoridade policial", a "proibição de se aproximarem os mesmos da faixa de fronteiras" e mesmo a "internação de todos os asilados e refugiados"13.

Com a entrada em operação do CIEX o Uruguai virou um território ainda mais vigiado e perigoso para os exilados brasileiros. Os exemplos abundam na documentação, sobretudo entre os anos de 1966 e 1968. Os informes coletados e as informações produzidas variavam do relevante ao absolutamente irrelevante. Desde a anotação de todos os automóveis com placa do Brasil que circulassem por Atlantida, onde residia Leonel Brizola ${ }^{14}$, até o relato detalhado de reuniões ou encontros entre os exilados, como foi o caso, por exemplo, do seguinte informe:

"1. Em 30/SET/66, às 9hs00, em Atlântida (ROU), os asilados ADILSON PINHEIRO PIMENTEL, GUIDO GURGEL, TITO GUIMARÃES FILHO, MANOEL LIVINIO RIBEIRO LEAL E GUALTER DE CASTRO MELO estabeleceram contatos com o asilado LEONEL DE MOURA BRIZOLA.

2. Por ocasião do encontro, LEONEL BRIZOLA disse que "a revolução brasileira acontecerá num prazo mais longo (sic)"; em seguida criticou JOÃO GOULART, dizendo entre outras coisas que GOULART era o único culpado de tudo que aconteceu. Finalizando, os asilados pediram a BRIZOLA uma ação mais positiva a fim de apressar a revolução brasileira. Em resposta, BRIZOLA pediu calma a todos e disse-lhes que esperassem a hora". ${ }^{15}$

Nota-se que havia uma preocupação especial em monitorar os passos dos exilados mais proeminentes. A leitura dos documentos indica uma vigilância

13 "Relaçôes políticas Brasil-Uruguai". Oficio n. 602 expedido pela Embaixada do Brasil em Montevidéu para a Secretaria de Estado. 21 de novembro de 1964. Arquivo do Ministério das Relações Exteriores, Ofícios Recebidos - 1964 - A/O, caixa 07 - Secreto.

14 Como consta, por exemplo, nos informes 551 ("Automóveis brasileiros em Atlântida. Leonel Brizola") e 552 ("Carros brasileiros circulando em Atlântida. Leonel Brizola"), ambos de 23 de novembro de 1966 e difundidos para o SNI, agência central, D-2/Gabinete do Ministro da Guerra e 2a seção do Estado Maior do Exército. Ambos classificados como Secreto. CIEX, vol. 2, 1966.

15 "Novos asilados estabelecem contatos com BRIZOLA. Atlântida". CIEX, n. 420, de 11 de outubro de 1966. Distribuição: ADITAR/ROU, SNI/ARJ, D-2/GabMG, 2a Seção EME. Secreto. CIEX, vol. 1, 1966. 
redobrada em torno de Leonel Brizola e de João Goulart, uma vez que os dois exerciam liderança sobre importantes grupos de exilados, dentro e fora do Uruguai, e também porque eram frequentemente procurados por simpatizantes que ainda estavam no Brasil.

Outra possibilidade de ação vislumbrada por parte dos exilados do Cone Sul e que efetivamente ocorreu em diversos casos foi o engajamento na luta pelo sonho socialista independente da nacionalidade do exilado. Alguns brasileiros, por exemplo, aliaram-se a grupos argentinos que combatiam a ditadura naquele país em nome do ideal socialista. O mesmo ocorria com militantes de outras nacionalidades agindo em países que não o seu. É conhecida a idéia de que o socialismo, em termos doutrinários, é contra a idéia nacionalista, encarada como mais um dos elementos constituintes do arcabouço de dominação capitalista. Nesse sentido, nada mais natural que o envolvimento político em qualquer parte do mundo, uma vez que isso reforça a luta contra a opressão e contribui para união do proletariado enquanto classe universal.

O que a maior parte dos militantes de esquerda não esperava era que a direita também se organizasse de maneira tão eficaz para agir internacionalmente. A "direita", nesse caso, era representada pelos militares que haviam tomado o poder e que, enquanto uma categoria específica dotada de elementos convergentes, puderam e efetivamente atuaram de forma transnacional. Naturalmente a convergência desses setores militares não era completa. No que dizia respeito ao princípio nacionalista, elemento basilar de praticamente todas as doutrinas castrenses, os militares se distanciavam. É até um paradoxo observar como a idéia de guerra "anticomunista" conseguiu prevalecer sobre divergências tão profundas que marcavam a história de toda a região do Cone Sul. Basta lembrar as hipóteses de guerra desenvolvidas tanto por militares brasileiros quanto por argentinos, de sorte que ambos previam e se preparavam para uma guerra entre os dois países. Igualmente, as diferenças entre argentinos e chilenos eram profundas, sendo que ambos disputavam territórios considerados em litígio e se preparavam, nem sempre discretamente, para um possível conflito. Nem essas diferenças de fundo foram capazes de impedir a cooperação em torno da perseguição àqueles que eram considerados subversivos, independente da nacionalidade ou de onde estivessem.

\section{Brasil e Argentina: espionar e punir}

No Brasil, a ditadura militar que assumiu o poder em março de 1964, além de promover a mudança do regime e suprimir o Estado democrático, foi profundamente marcada pela violência utilizada como método para conter a oposição e garantir a manutenção da nova ordem que foi ditada ao país.

Com efeito, 1964 tornou-se um marco na história contemporânea brasileira.

O Golpe de Estado desferido contra o governo do presidente João Goulart 
significou a ruptura com a democracia instalada no país após a Segunda Guerra Mundial. Significou, também, o coroamento do processo conflituoso entre camadas da sociedade civil e projetos políticos opostos vislumbrados para o Brasil pelos setores sociais mais organizados.

Um outro elemento que ajudou a acirrar as contradições internas da sociedade brasileira, e que levou ao Golpe de Estado, foi o contexto internacional bipolar, no qual a estrutura básica da Guerra Fria, profundamente marcada pela intensificação das diferenças ideológicas, certamente potencializou uma situação de conflito com amplas repercussões na vida política nacional. Aliás, esse fenômeno ocorreu também nos demais países da região do Cone Sul, tendo como exceção apenas o caso paraguaio, um pouco diverso dos demais.

Os anos compreendidos entre 61 e 64 foram, sem dúvida, responsáveis pelos mais férteis debates ideológicos na vida política nacional. Em poucos momentos da história brasileira registraram-se tantas discussões envolvendo a questão social e com alto grau de conscientização política, com intensa participação dos sindicatos, movimento estudantil e partidos políticos de cunho nacionalista e socialista. Foi o período, inclusive, que até mesmo a política externa, historicamente elitizada no Brasil, ganhou as ruas e virou mote de discussão em agremiações estudantis, sindicatos e partidos políticos.

A renúncia de Jânio Quadros e sua substituição por João Goulart, um político identificado com o trabalhismo getulista e até certo ponto aberto à participação dos partidos de esquerda, ajudaram a compor um quadro ainda mais complexo. Por seu turno, os partidos políticos tradicionais de cunho liberal e as diversas associaçóes empresariais, considerando que algumas delas chegaram à sofisticação de estruturar institutos de pesquisa e organizações voltadas para a análise da conjuntura política nacional, comprovam que também estavam se instrumentalizando racionalmente para o embate ideológico e o clima de conspiração que vinha envolvendo o conjunto da sociedade brasileira nos agitados anos 1960 .

Muito embora os setores conservadores da sociedade brasileira, tendo à frente $\mathrm{o}$ Exército, tenham manobrado para que o vice presidente não assumisse $\mathrm{o}$ poder após a renúncia de Jânio Quadros (Goulart havia sido eleito vice-presidente na chapa do candidato derrotado, Marechal Lott, e estava em viagem oficial à China comunista quando da renúncia de Quadros,) o que sugere um elemento a mais a compor a trama da renúncia, uma vez que Quadros conhecia muito bem a aversão que o oficialato, especialmente do Exército e da Aeronáutica, nutriam por tudo que lembrasse o getulismo -, a pressão popular e a resistência montada pelo então governador do Rio Grande do Sul, Leonel Brizola, forçaram uma solução alternativa negociada, e não somente de força, para o impasse criado pela renúncia. De qualquer forma, desde o momento inicial da crise de 1961, ficou patente que havia, por parte de uma camada influente de altos oficiais do Exército, o descontentamento com os rumos políticos que se anunciavam com a ascensão de Goulart à presidência. 
Não só os militares passaram a conspirar contra o governo do herdeiro político de Getúlio Vargas. Considerável parcela da elite política nacional desde cedo demonstrou preocupação com a possível guinada política que o governo poderia dar para atender aos anseios da parcela menos favorecida da população, angariando, dessa forma, o necessário apoio popular para a implementação de reformas estruturais, dentre as quais a agrária e a bancária. Assim, a parte mais ativa do empresariado nacional envolveu-se diretamente na conspiração para a derrubada do governo Goulart, contando para tanto com o poder financeiro e o suporte internacional prontamente oferecido pelos Estados Unidos da América.

Em 1964 o presidente Goulart foi deposto e os militares, associados com os setores organizados do empresariado nacional, retomaram o comando político do Estado. O Golpe forçou o exílio de expressiva parcela de políticos e colaboradores comprometidos com o governo de João Goulart, enquanto uma parte dos militantes dos partidos de esquerda e de movimentos sociais optou pela permanência no país e por açôes políticas de denúncia e de combate ao regime ditatorial. Em pouco tempo começou a contestação violenta contra o regime e, da mesma forma, a reação do lado do Estado autoritário.

No Brasil, a natureza do regime instaurado em 1964 implicou na montagem de um amplo e complexo sistema de informações que teve como objetivo primordial a manutenção do poder militar. Gradativamente, os militares constituíram um verdadeiro sistema de informações que abrangia não só todo o país mas que ia além, operando no exterior com o suporte do Ministério das Relações Exteriores. Não há paralelo ao sistema de informações montado pela ditadura brasileira, pelo menos não na região do Cone Sul. A eficiência desse sistema pode ser comprovada, por exemplo, pelo fato de que o regime militar no Brasil conseguiu manter sob controle os movimentos de esquerda que lutavam contra a ditadura, seja no cenário urbano ou no rural.

O objetivo principal do Sistema Nacional de Informações, ao contrário dos serviços de informação de Estados democráticos, que em tese possuem como atribuição principal a defesa do Estado contra ações de natureza espúria (como ações terroristas, especulações financeiras, ingerências externas e inserção estratégica internacional), era o de zelar pela manutenção dos sucessivos governos autoritários que se revezaram no poder entre 1964 e 1984.

O órgão centralizador desse sistema foi o Serviço Nacional de Informaçōes (SNI). O SNI centralizava e sistematizava os informes e as informações processadas pelos serviços secretos dos Ministérios militares e pelas Divisões de Segurança Interna (DSI) criadas no âmbito dos Ministérios civis e pelos Departamentos de Ordem Política e Social (DOPS), o braço armado civil do regime militar. Além disso, há que se observar a atuação constante e, por vezes, competitiva entre os centros de informações de natureza estritamente militar, relacionados às três forças armadas do país e que dispunham de serviços próprios de informaçôes. Com o passar do tempo e a consolidação do poder militar no país, essas agências foram 
ganhando mais autonomia e importância em suas respectivas armas e no sistema como um todo, operando muitas das vezes de forma completamente autônoma e visando a objetivos próprios, não necessariamente orientados pelo SNI.

Assim, a estrutura principal até o momento conhecida da comunidade nacional de informações considerava o SNI, visto como o elemento central da "inteligência" brasileira, auxiliado pelos demais órgãos setoriais, a saber: o Centro de Informações do Exército (CIE), o Centro de Informações da Marinha (Cenimar), o Centro de Informações e Segurança da Aeronáutica (CISA), as diversas Divisões de Segurança Interna (DSI), as Assessorias de Segurança e Informações (ASI), as FA-2 (Segunda Seção do Estado Maior das Forças Armadas - EMFA), os E-2 (Serviços Secretos do Exército), os M-2 (Serviços Secretos da Marinha), os A-2 (Serviços Secretos da Aeronáutica), as S-2 (Segundas Seções dos três Ministérios militares, os Departamentos de Ordem Política e Social (DEOPS), as P-2 (Serviços Secretos da Polícia Militar), os Serviços Secretos da Polícia Federal e os CODIs-DOIs (Centros de Operações de Defesa Interna - Destacamentos de Operaçõos Internas). ${ }^{16}$

Todos esses organismos atuavam na coleta de informaçóes no plano interno, objetivando descobrir e eventualmente eliminar os focos de resistência à ditadura, por mais tênues que fossem. Para o desempenho dessas funções, um dos métodos utilizados com freqüência foi a tortura física e psicológica, levada às últimas conseqüências. Além disso, naturalmente, via de regra operavam ao arrepio da lei, geralmente não prestando contas dos seus atos a não ser a seus superiores imediatos.

O fato é que além da tortura cada vez mais generalizada e, ao mesmo tempo, mais especializada, foi montado no Brasil um eficiente serviço de informação. Essa estrutura diferia-se, naturalmente, das mais conhecidas agências internacionais, como a norte-americana CIA, a soviética KGB, o israelense Mossad e o britânico MI6, só para citarmos os mais renomados e conhecidos. No caso brasileiro, o SNI e seus afiliados se especializaram muito mais na atuação interna, ou seja, na repressão aos que lutavam ou discordavam da ditadura militar e não na ação de espionagem internacional contra outros Estados.

Essa é uma diferença importante a se destacar e que coadunava perfeitamente com a ideologia da segurança nacional, em vigor em boa parte da América Latina. Aliás, as próprias Forças Armadas brasileiras ao longo de sua história estiveram muito mais envolvidas no controle da ordem interna do que em efetivo emprego no exterior, combatendo em nome da pátria ou defendendo a soberania nacional.

No século XX, por exemplo, além do emprego em Missóes de Paz das Nações Unidas, os militares brasileiros atuaram de fato apenas na Segunda Guerra Mundial (no caso brasileiro, entre 1944 e 1945), com um modesto efetivo de aproximadamente 25 mil homens, e na intervenção patrocinada pelos Estados Unidos da América e sob os auspícios da Organização dos Estados Americanos

16 Cf. LAGÔA, Ana. SNI como nasceu como funciona. São Paulo: Brasiliense, 1983, p. 35. Para uma análise mais detalhada do SNI ver: FIGUEIREDO, Lucas. Ministério do silêncio - a história do serviço secreto brasileiro, de Washington Luis a Lula (1927-2005). Rio de Janeiro: Record, 2005. 
(OEA) na ilha de Santo Domingo, em 1965. Já internamente as intervenções foram muito mais marcantes.

Paralelamente à atuação dos serviços de informação que operavam no plano interno, o regime militar brasileiro criou também uma agência especializada para atuação no plano externo. Até hoje praticamente ignorado pela historiografia sobre o Golpe de Estado de 1964, o Centro de Informações do Exterior - CIEX - ${ }^{17}$ recebeu a incumbência de acompanhar as atividades dos "subversivos" brasileiros que, apesar do exílio, continuavam protestando contra a falta de liberdade política no Brasil e denunciando os maus tratos impostos pelo regime contra os seus oponentes, como sublinhado anteriormente.

Mas além da tortura, que embora banalizada e aceita pelos novos donos do poder como uma poderosa ferramenta no que consideravam ser uma verdadeira guerra contra a subversão pela qual passava o Brasil, a ditadura contou também com outros instrumentos de intimidação, em muitos aspectos mais eficientes que a tortura, haja vista que esta era uma medida extrema e a decisão de torturar demonstra que os outros meios de se obter as informaçôes ou confissões desejadas haviam falhado. É importante ressalvar, contudo, que em vários momentos houve, de fato, uma generalização e completa banalização do ato de torturar, o que prova a decrepitude moral do regime de exceção instalado no Brasil sob comando inequívoco dos militares, embora nunca seja demais relembrar e reafirmar a conivência e cooperação de muitos setores civis da sociedade que comungavam in extremis com a forma de pensar e agir dos militares.

Muito embora as atividades do CIEX não se resumissem exclusivamente ao acompanhamento e monitoramento das atividades de brasileiros no exterior, elas se constituíam, de fato, na principal atividade do Centro, o que claramente o distinguia dos demais órgãos da comunidade de informações.

$\mathrm{Na}$ Argentina, o processo de radicalização política se acelerou a partir de 1969, quando atores políticos e sociais intensificaram a crítica à estrutura política econômica e social então vigente. Como salienta Novaro, entre 1969 e 1976 a história argentina foi marcada pelo fracasso democrático e pelo conseqüente triunfo de soluções extremas ${ }^{18}$.

A crise argentina, que já vinha de antes, acabou se acentuando com o chamado Cordobazo, uma insurreição de trabalhadores e estudantes em 1969 na província de Córdoba, fato que desencadeou um série de convulsões políticas e sociais no país. Após esse episódio, as condiçôes econômicas e políticas voltaram a se deteriorar e alguns grupos, como os Montoneros e o Ejercito Revolucionario del Pueblo (ERP) partiram para a radicalização do movimento de contestação da ordem vigente.

17 Geralmente é muito comum a confusão entre o CIE, que era o Centro de Informaçôes do Exército, e o CIEX, este vinculado ao Ministério das Relaçôes Exteriores. Tal confusão se dá pela ausência de trabalhos e referências sobre a atuação do CIEX.

18 NOVARO, Marcos. História de La Argentina Contemporânea-De Perón a Kirchner. Buenos Aires: Edhasa, 2006, p. 45. 
É interessante notar que em contraposição ao Brasil, na Argentina a radicalização dos grupos de esquerda aconteceu antes do golpe militar.

Essas questôes voltaram a preocupar as Forças Armadas e, deste modo, proporcionou-se a tomada do poder em 1976 promovido pela Junta Militar, encabeçada pelo General Rafael Videla. Os militares argentinos usaram o pomposo título de Processo de Reorganização Nacional para o Golpe de Estado.

Como não havia grande contingente de brasileiros na Argentina, as atividades do CIEX naquele país se distinguiram se comparadas às desempenhadas no Uruguai e no Chile. Acompanhando a evolução do quadro político argentino, ainda em setembro de 1976, o Centro avaliava a brutalidade dos militares argentinos e questionava, inclusive, se o regime conseguiria se sustentar por muito mais tempo, haja vista que não "era segredo para ninguém que as forças de segurança têm procedido desde o 24 de março à eliminação sistemática de prisioneiros e/ ou suspeitos de atividades subversivas". Indo além, o informe em questão anotava que segundo fontes "dignas de confiança, o número de eliminação física já teria ultrapassado a casa dos cinco mil”. ${ }^{19}$

Presente nas demandas dos movimentos sociais e setores políticos organizados em partidos ou grupos que contestavam a ordem estava o repúdio ao militarismo e a expectativa de que o sonho socialista pudesse finalmente se realizar na Argentina. Como nos outros países sul-americanos, a Argentina também estava inserida num modelo de desenvolvimento periférico e desigual, o que acarretava demandas sociais que não eram consideradas essenciais pelo Estado.

Ao passo que a esquerda se movimentava e radicalizava, a direita argentina também estava se mobilizando. Como destaca Mangini, em 1973 um grupo paramilitar de ultradireita chamado Alianza Anticomunisata Argentina (AAA), também conhecido como Triple $A$, levou a cabo vários atentados contra pessoas ligadas a alas progressistas e de esquerda do País. Ainda segundo o autor, a Triple A contava com pessoas ligadas ao governo peronista e também com membros da Escola de Mecânica da Armada (ESMA), que ficaria famosa mais tarde por ter sido um importante centro de tortura no país ${ }^{20}$.

O golpe de Estado, todavia, colocou em marcha um plano de ação que previa uma guerra total a todos esses setores que passaram a ser vistos como uma verdadeira ameaça ao Estado nacional argentino. Nesse sentido, os militares argentinos implementaram um verdadeiro Terrorismo de Estado ${ }^{21}$, no qual não

19 "Argentina: Política interna. Avaliação de conjuntura". Informe n. 341/76, de 20 de setembro de 1976. Difusão: SNI/AC, CIE, $2^{a}$ Seção/EME, $2^{a}$ Seção/EMAER, CENIMAR, 2a Seção/EMA, CISA, Ass/Ch AC/ SNI. Secreto. CIEX, vol. 24, 1976.

20 FERNANDES, Julio Mangini. A repressão aos exilados brasileiros no exterior: a ação do CIEX na Argentina (1974-1976). Cuiabá: UFMT, 2006. Monografia de final de curso (Graduação em História), p. 22-23. Um exemplo de assassinato praticado pela Triple A foi o caso do sindicalista Atílio López.

21 A esse respeito ver: PASCUAL, Alejandra Leonor. Terrorismo de Estado: A Argentina de 1976 a 1983. Brasília: EdUnb, 2004. 
faltaram elementos de desmesurada violência, não só contra militantes de esquerda, mas também com suas famílias numa atitude que extrapolou todas as demais ditaduras do Cone Sul.

Fora as ações militares que foram pautadas pela extrema violência, os novos governantes argentinos também promoveram reformas econômicas que não foram bem sucedidas e nem consensuais, além de que remodelaram, de acordo com seus interesses, os poderes Judiciário e Legislativo. Tirando a estrutura econômica que não foi de todo transformada, haja vista que o Estado militar garantia a existência dos valores capitalistas, o novo governo teve de fazer frente a uma série de problemas que afetavam a economia argentina e geraram uma grise de graves proporções, como por exemplo inflação em alta, recessão e dificuldades com a balança de pagamentos. Como destaca Luis Alberto Romero, esses problemas acabavam agravando ainda mais a crise política e social no país ${ }^{22}$. Destaque-se, por exemplo, o crescente número de greves operárias em diversos setores, reflexo da mobilização da classe operária que, além das reivindicações econômicas também passaram a valorizar crescentemente sua pauta política. Tudo isso abriu caminho e serviu como justificativa para o envolvimento militar nos assuntos políticos da Argentina, ainda mais quando consideramos o pano de fundo da Guerra Fria e o contexto regional, no qual todos os demais países já haviam mudado de regime.

Contudo, o aspecto mais importante que se pretende destacar neste artigo está relacionado com a violência institucional criada pelos militares argentinos. Embora todas as ditaduras militares tenham se pautado basicamente pela violência institucionalizada como forma de controle da sociedade pelo Estado, os regimes argentino e chileno superaram em muito os demais. Foram muitos os casos de intimidaçôes, torturas, seqüestros, desaparecimentos, assassinatos e toda sorte de brutalidade imaginável ${ }^{23}$.

Como destaca Quiroga, além de fechar o Parlamento e estabelecer uma ordem militar, o Estado autoritário organizou uma estrutura repressiva nunca antes vista na história argentina, criando uma estrutura paralela e oculta que administrava "centros clandestinos de detenção" e "grupos operacionais secretos", o que levou ao abuso sistemático dos mais elementares direitos humanos ${ }^{24}$.

Nesse sentido, a militância de esquerda e mesmo as pessoas que não militavam, mas que tinham alguma participação política, ficaram intimidadas pelo regime e a tendência foi o isolamento da vida política, uma vez que o risco de perder a

22 Cf. ROMERO, Luis Alberto. Breve historia contemporánea de la Argentina. Buenos Aires: Fondo de Cultura Económica de Argentina, 2005, p. 212.

23 Um relato pormenorizado da brutalidade do regime pode ser encontrada no livro Nunca Más, uma publicação da Comissão Nacional sobre o Desaparecimento de Pessoas e que equivale à publicação brasileira Nunca Mais. Cf. CONADEP. Nunca más: informe de la Comisión Nacional sobre la desaparición de personas. Buenos Aires: Eudeba, 2006.

24 Cf. QUIROGA, Hugo. “El Tiempo del 'Proceso'. In: SURIANO, Juan (dir.) Nueva História Argentina - Dictadura y Democracia (1976-2001). Buenos Aires: Sudamericana, 2005, p.57. 
liberdade ou mesmo a vida era algo certo. Isso se refletiu, por exemplo, numa onda impressionante de refugiados que deixaram rapidamente o país. Segundo dados produzidos pelo Alto Comissariado das Naçôes Unidas para Refugiados (ACNUR) e transmitidos pelo CIEX para as autoridades brasileiras, somente nos meses de junho, julho e agosto de 1976, 768 pessoas deixaram oficialmente a Argentina como refugiados políticos ${ }^{25}$. Mesmo antes do Golpe os argentinos já haviam experimentado o estado de sítio e muito da repressão que viria de forma sistemática após 1976.

Como agravante desse quadro, a crise econômica que atingiu o país no final dos anos 70 e sobretudo no início da década seguinte (na verdade a crise atingiu praticamente toda a América Latina), associada ao nacionalismo ufanista pregado pelos militares resultou em mais sofrimento com a atitude mal calculada e desesperada dos setores dominantes castrenses de tentarem retomar à força o controle das Ilhas Malvinas, o que resultou na guerra contra a Inglaterra e na morte de centenas de jovens soldados despreparados que foram enviados para a frente de batalha sem praticamente nenhuma preparação para enfrentar o experiente exército britânico ${ }^{26}$.

O ciclo militar argentino durou pouco tempo se comparado às ditaduras no Paraguai, no Brasil, no Uruguai e no Chile, mas foi capaz de extrapolar, em termos de desrespeito aos direitos humanos e pela quantidade de pessoas assassinadas, em muito, as demais ditaduras do Cone $\mathrm{Sul}^{27}$. Milhares foram os que perderam a vida por acreditarem que era possível uma alternativa à desigualdade e à opressão gerada por um sistema capitalista periférico e excludente.

Recebido em 02 de Marco de 2009 Aprovado em 10 de setembro de 2009

25 "Refugiados políticos. Viagem para diversos países". Informe n. 334/76, de 24 de setembro de 1976. Difusão: SNI/AC, CIE, 2 $2^{a}$ Seção/EME, 2 $2^{a}$ Seção/EMAER, CENIMAR, 2a Seção/EMA, CISA, Ass/Ch AC/SNI. Secreto. CIEX, vol. 24, 1976. Segundo esse informe os países que receberam os refugiados foram os seguintes: Alemanha (5), Argélia (28), Áustria (8), Austrália (9), Bélgica (30), Brasil (4), Canadá (178), Cuba (98), Dinamarca (6), Espanha (1), França (74), Grã-Bretanha (23), Israel (5), Itália (2), México (50), Noruega (25), Nova Zelândia (28), Países Baixos (56), Portugal (2), Suécia (111), Suíça (2), União Soviética (7) e Venezuela (16).

26 De acordo com Luis Romero a Guerra das Malvinas deixou mais de 700 mortos ou desaparecidos e quase 1.300 feridos. Cf. ROMERO, Luis Alberto. Breve historia contemporánea de la Argentina. Buenos Aires: Fondo de Cultura Económica de Argentina, 2005, p.235.

27 Segundo algumas estimativas o saldo de mortos e desaparecidos na Argentina varia de 9.000 (dados oficiais) a 30.000 (de acordo com organismos de direitos humanos) pessoas. Cf. ARAÚJO, Maria Celina de \& CASTRO, Celso (org). Democracia e Forças Armadas no Cone Sul. Rio de Janeiro: Editora FGV, 2000, pg. 314. 


\section{Referências bibliográficas}

D’ARAÚJO, Maria Celina \& CASTRO, Celso (org). Democracia e Forças Armadas no Cone Sul. Rio de Janeiro: Editora FGV, 2000.

D’ARAUJO, Maria Celina; SOARES, Gláucio Ary Dillon; CASTRO, Celso. Os anos de chumbo - a memória militar sobre a repressão. Rio de Janeiro: Relume-Dumará, 1994.

CONADEP. Nunca más: informe de la Comisión Nacional sobre la desaparición de personas. Buenos Aires: Eudeba, 2006.

DINGES, John. Operación Condor - una década de terrorismo internacional en el Cono Sur. Santiago: Crônica Atual, 2004.

FERNANDES, Julio Mangini. A repressão aos exilados brasileiros no exterior: a ação do CIEX na Argentina (1974-1976). Cuiabá: UFMT, 2006. Monografia de final de curso (Graduação em História).

FIGUEIREDO, Lucas. Ministério do silêncio - a história do serviço secreto brasileiro - de Washington Luis a Lula, 1927-2005. Rio de Janeiro: Record, 2005.

GUENA, Márcia. Arquivo do horror - Documentos secretos da ditadura do Paraguai (19601980). São Paulo: Memorial da América Latina, 1996.

LAGÔA, Ana. SNI como nasceu como funciona. São Paulo: Brasiliense, 1983.

NOVARO, Marcos. História de La Argentina Contemporânea - De Perón a Kirchner. Buenos Aires: Edhasa, 2006.

PASCUAL, Alejandra Leonor. Terrorismo de Estado: a Argentina de 1976 a 1983.

Brasília: EdUnb, 2004.

PENNA FILHO, Pio. "O Itamaraty e a repressão além-fronteiras: o Centro de Informações do Exterior - CIEX (1966-1986)”. In: SEMINÁRIO 40 ANOS DO

GOLPE DE 1964 (2004: Niterói e Rio de Janeiro). Rio de Janeiro: 7 Letras, 2004.

QUADRAT, Samantha Viz. “Os porões internacionais da repressão”. In:

SEMINÁRIO 40 ANOS DO GOLPE DE 1964 (2004: Niterói e Rio de Janeiro). Rio de Janeiro: 7 Letras, 2004.

QUIROGA, Hugo. “El Tiempo del 'Proceso'. In: SURIANO, Juan (dir.) Nueva História Argentina - Dictadura y Democracia (1976-2001). Buenos Aires: Sudamericana, 2005.

ROMERO, Luis Alberto. Breve historia contemporánea de la Argentina. Buenos Aires: Fondo de Cultura Económica de Argentina, 2005.

\section{Resumo}

Neste artigo, examina-se o funcionamento do Centro de Informações do Exterior (CIEX), órgão do Itamaraty e vinculado ao Serviço Nacional de Informações (SNI) que foi encarregado de espionar políticos e militantes contrários ao regime militar brasileiro que se exilaram nos países vizinhos. Trata-se de um estudo que visa a desvendar como agia um dos elos do sistema repressivo montado pela ditadura brasileira, que tinha um 
relativo grau de interação com as outras ditaduras militares da região do Cone Sul. O artigo demonstra que o Itamaraty colaborou intensamente com o regime militar brasileiro, inclusive com a repressão.

\section{Abstract}

This paper analyzes the functioning of the Centro de Informações do Exterior (CIEX), an agency linked to the Ministry of Foreign Affairs (Itamaraty) and National Intelligence Service (SNI), which was charged with spying political opponents of the Brazilian military regime exiled in neighboring countries. The study aims at examining one component of the repressive system set by the Brazilian dictatorship that had a relative degree of interaction with other military dictatorships in the region of the Southern Cone. The article demonstrates that the Ministry of Foreign Affairs cooperated intensively with the Brazilian military regime.

Palavras chave: Ditadura; Regime Militar; Itamaraty; Repressão; CIEX.

Keywords: Dictatorship; Military regime; Itamaraty; repression; CIEX. 